\title{
MicROVASCULAR DENSITY AND MAST CELLS IN BENIGN AND MALIGNANT PHEOCHROMOCYTOMAS
}

\author{
Magdalena Bialas, Grzegorz Dyduch, Joanna Szpor, Sergiusz Demczuk, Krzysztof Okoń
}

Chair of Pathomorphology, Jagiellonian University Medical College, Cracow, Poland

\begin{abstract}
Pheochromocytomas, uncommon adrenal tumors, have an uncertain behavior. Recently, PASS criteria were proposed for differentiating between benign and malignant cases. These are not perfect, however. The aim of the study was to investigate angiogenesis and mast cell density in context of the clinical behavior and morphologic characteristics of pheochromocytomas.

Mean intratumoral chymase positive cell count was 14.50 for malignant, 15.73 for benign cases; mean subcapsular chymase positive cell count was 12.50 for malignant, 11.27 for benign cases. Mean intratumoral tryptase positive cell count was 17.50 for malignant and 17.91 for benign cases; mean subcapsular tryptase positive cell count was 15.25 for malignant and 15.73 for benign cases. Mean intratumoral CD31 positive vessel count was 46.98 for malignant and 51.02 for benign cases; mean subcapsular CD 31 positive vessel count was 44.86 for malignant and 39.81 for benign cases. Mean intratumoral CD105 positive vessel count was 37.84 for malignant and 35.95 for benign cases; mean subcapsular CD105 positive vessel count was 26.36 for malignant and 22.03 for benign cases. The differences between benign and malignant cases were not significant. All the vascular counts were correlated with mast cells counts. PASS index was inversely correlated with mast cell counts.
\end{abstract}

Key words: pheochromocytoma, mast cells, angiogenesis, microvessels density.

\section{Introduction}

Pheochromocytomas are rare tumors arising from sympathochromaffin cells of adrenal medulla. The same tumors deriving from chromaffin cells in extraadrenal locations are called paragangliomas (extraadrenal pheochromocytomas). Most of pheochromocytomas behave in a benign fashion; the prevalence of malignancy ranges from $2.5 \%$ to $25 \%$ of cases [1]. The distinction between malignant and benign pheochromocytomas was traditionally regarded as particularly difficult. The only valid criterion was a clinically detectable metastasis, defined as the presence of tumor cells in sites where chromaffin cells are normally absent or recurrent disease [1-3]. Indeed this remains a difficult issue; to aid this, several scoring systems were created. These systems used local invasion, histological growth patterns, cytological features or mitotic activity as criteria for as- sessing the risk of malignant behavior. Currently, the most widely used multifactorial histological system is PASS proposed by Thompson [4]. It seems to show fairly good performance, nevertheless no current score system predicts aggressive behavior unequivocally [5]. As a consequence, lifelong follow-up is necessary in all cases to assure early detection and treatment of metastases. This leads to excessive health system expenses and unnecessary anxiety of patients.

Angiogenesis is essential for tumor growth and metastasis formation. It is assumed that cancers, after an early vasculogenic phase, acquire ability to induce new vessels formation, this is followed by accelerated growth and clinically apparent tumor. Such phenomenon is referred to as angiogenic switch. Angiogenic switch depends on the ability to release specific growth factors stimulating blood vessels formation as well as down-regulation of inhibitors. The source of those fac- 
tors is both neoplastic cells and various stromal and immune cells, like macrophages and mast cells. Although mast cells are not the most numerous cell population of tumor stroma, they produce a plethora of pro-angiogenic and tissue-remodeling factors. They may thus participate in tumor growth stimulation, tumor growth inhibition, angiogenesis as well as antitumor immune response. As a consequence, depending on the tumor type and location within the tumor, mast cells density may show a positive or negative correlation with tumor progression [6]. What is more, mast cells do not constitute a homogenous population, as their two main subsets, chymase-positive and tryptase-positive ones may have different functions.

Angiogenesis is a complex phenomenon, therefore many strategies are used to evaluate its role in tumor progression. For a pathologist, the most standard group of methods consists of assessing microvessel density (MVD), total microvascular area, vascular patterns and expression of angiogenic factors to assess their diagnostic and prognostic significance $[7,8]$. Still, the overall significance of angiogenesis remains incompletely understood. In some cancers, like breast cancer, tumors with a more extensive vascular network behave more aggressively, while in other, like renal cell carcinoma, the relationship is inverse. What is more, most studies of angiogenesis deal with highly aggressive, common cancers [9].

The aim of our study was to investigate the number of tryptase-positive and chymase-positive mast cells, density of CD31-positive and CD105-positive blood vessels and to correlate these findings with morphologic parameters and clinical behavior in adrenal pheochromocytomas. In particular, we wanted to verify whether any of the vascular- or mast cell-related parameters was related to the malignant clinical course.

\section{Material and methods}

The material consisted of 15 pheochromocytomas found in the files of the Department of Pathomorphology UJCM in Cracow. The material was fixed in formalin, routinely processed and paraffin embedded. All cases were reevaluated by a pathologist experienced in adrenal pathology (MB). PASS score was assessed as defined by Thompson [4]. Clinical data were derived from patients' records; malignant behavior was defined as formation of metastases or local tumor recurrence.

Table I. Primary antibodies used in the study

\begin{tabular}{llll}
\hline SPECIFICITY & ClONE & MANUfACTURER & Dilution \\
\hline CD31 & JC70A & DAKO & $1: 20$ \\
\hline CD105 & 4G11 & Novocastra & $1: 50$ \\
\hline Chymase & CC1 & Abcam & $1: 100$ \\
\hline Tryptase & AA1 & Novocastra & $1: 100$ \\
\hline
\end{tabular}

In each case, a single section including well-preserved tumor tissue as well as tumor capsule were chosen. From the tissue blocks, $3 \mu \mathrm{m}$ sections were prepared.

Immunohistochemistry was performed by a standard method. Briefly, the slides were dewaxed, rehydrated and incubated in $3 \%$ peroxide solution for 10 minutes to block endogenous peroxidase activity. Antigen retrieval was carried out by microwaving in citrate buffer (pH 6.0) for 5 minutes at $700 \mathrm{~W}$, then for 5 minutes at $600 \mathrm{~W}$ for chymase stain and by trypsin digestion $\left(30 \mathrm{~min}\right.$ at $37^{\circ} \mathrm{C}$ ) for tryptase stain. Primary antibodies are listed in Table I. The LabVision (Thermo Fisher Scientific, USA) detection system was used. 3-amino9-ethylcarbasole served as the chromogen. The slides were counterstained with Mayer's hematoxylin (DAKO, Denmark).

For assessment of the immunohistochemistry, the subcapsular space was defined as the area within one high power field $(0.5 \mathrm{~mm})$ beneath the tumor outer border, and the remainder of the tumor as intratumoral space. Tryptase-positive mast cells and chymase-positive mast cells were counted both in peri- and intratumoral space using an Olympus BX51 microscope equipped with a $40 \times$ UPlanFLN eyepiece (field of view diameter $0.55 \mathrm{~mm}$ ). For each parameter, 10 high power fields were assessed. The results were expressed as a number of cells per square millimeter. For assessment of the microvessel density, morphologically identifiable vessels, collections of immunopositive cells as well as single endothelial cells were counted. For each parameter, 10 high power fields were assessed. For subcapsular count these were consecutive fields, while for intratumoral count a pre-scanning was done on low magnification to choose an area with the highest vascular density ('hot spot'). The results were expressed as a number of cells per square millimeter.

Statistical analysis was performed using Statistica 10 (StatSoft Inc., USA). The comparison between groups was done with Mann-Whitney U test; the relationship between variables was assessed using Spearman's correlation coefficient. The significance level was set at 0.05 .

\section{Results}

The material under study consisted of 15 cases of adrenal pheochromocytomas. There were 10 females and 5 males. The age of the patients ranged from 28 to 73 years (mean 56.2, SD 18.5). Males were slightly older than women (56.2 vs. 50.2) but this difference did not reach statistic significance. Eleven tumors were located at the right side, 3 at the left and in one case laterality was not stated. Two patients fulfilled the criteria for neurofibromatosis type I. The tumor diameter ranged from 2.5 to $13 \mathrm{~cm}$ (mean 4.85, SD 2.74). The tumor diameter was inversely correlated to age of 
Table II. Counts of chymase- and tryptase-positive mast cells

\begin{tabular}{|c|c|c|c|c|c|c|c|c|c|c|c|c|c|c|c|c|}
\hline & \multicolumn{8}{|c|}{ CHYMASE } & \multicolumn{8}{|c|}{ TRYPTASE } \\
\hline & \multicolumn{4}{|c|}{ INTRATUMORAL } & \multicolumn{4}{|c|}{ SUBCAPSULAR } & \multicolumn{4}{|c|}{ INTRATUMORAL } & \multicolumn{4}{|c|}{ SUBCAPSULAR } \\
\hline & MEAN & $\mathrm{SD}$ & MIN & MAX & MEAN & $\mathrm{SD}$ & MIN & MAX & MEAN & $\mathrm{SD}$ & MIN & MAX & MEAN & $\mathrm{SD}$ & MIN & MAX \\
\hline $\begin{array}{l}\text { mali- } \\
\text { gnant }\end{array}$ & 14.50 & 5.26 & 7.00 & 19.00 & 12.50 & 4.36 & 9.00 & 18.00 & 17.50 & 7.68 & 6.00 & 22.00 & 15.25 & 11.87 & 1.00 & 30.00 \\
\hline benign & 15.73 & 14.20 & 0.00 & 39.00 & 11.27 & 14.67 & 0.00 & 50.00 & 17.91 & 18.65 & 3.00 & 64.00 & 15.73 & 16.82 & 0.00 & 57.00 \\
\hline all cases & 15.40 & 12.26 & 0.00 & 39.00 & 11.60 & 12.57 & 0.00 & 50.00 & 17.80 & 16.16 & 3.00 & 64.00 & 15.60 & 15.24 & 0.00 & 57.00 \\
\hline
\end{tabular}

SD stands for standard deviation

Table III. Counts of CD31- and CD105-positive vessels

\begin{tabular}{|c|c|c|c|c|c|c|c|c|c|c|c|c|c|c|c|c|}
\hline & \multicolumn{8}{|c|}{ CD31 } & \multicolumn{8}{|c|}{$\begin{array}{r}\text { CD105 } \\
\end{array}$} \\
\hline & \multicolumn{4}{|c|}{ INTRATUMORAL } & \multicolumn{4}{|c|}{ SUBCAPSULAR } & \multicolumn{4}{|c|}{ INTRATUMORAL } & \multicolumn{4}{|c|}{ SUBCAPSULAR } \\
\hline & MEAN & $\mathrm{SD}$ & MIN & MAX & MEAN & $\mathrm{SD}$ & MIN & MAX & MEAN & $\mathrm{SD}$ & MIN & MAX & MEAN & SD & MIN & MAX \\
\hline $\begin{array}{l}\text { mali- } \\
\text { gnant }\end{array}$ & 46.98 & 15.30 & 36.56 & 69.73 & 44.86 & 14.70 & 31.46 & 65.48 & 37.84 & 14.67 & 25.51 & 56.97 & 26.36 & 4.45 & 20.41 & 29.76 \\
\hline benign & 51.02 & 17.62 & 27.21 & 79.08 & 39.81 & 14.11 & 20.41 & 64.63 & 35.95 & 13.49 & 14.46 & 59.52 & 22.03 & 12.12 & 0.00 & 40.82 \\
\hline all cases & 49.94 & 16.60 & 27.21 & 79.08 & 41.16 & 13.92 & 20.41 & 65.48 & 36.45 & 13.30 & 14.46 & 59.52 & 23.19 & 10.63 & 0.00 & 40.82 \\
\hline
\end{tabular}

the patients $(\mathrm{R}=-0.21)$ but this relationship was not statistically significant.

In 4 cases, malignant behavior was observed; these included one local relapse, one tumor spreading to the bone, lung and liver, one with liver metastases and one with metastases to contralateral adrenal. Patients with malignant tumors were somewhat younger ( 45.5 vs. 54.64 ) but this was not statistically significant. Malignant tumors were larger (average $8.13 \mathrm{~cm}$ vs. $3.66 \mathrm{~cm}$ ) and this difference was statistically significant $(\mathrm{U}=1.5, \mathrm{p}<0.01)$.

The mitotic count ranged from 0 to $40 / 10 \mathrm{HPF}$ (mean 4.26, SD 10.26). Mitotic figures were much more numerous in malignant lesions (14 vs. 0.72$)$ and this difference was statistically significant $(\mathrm{U}=3.0, \mathrm{p}<0.011)$. Mitotic activity was positively correlated with the tumor diameter $(\mathrm{R}=0.62, \mathrm{p}<0.015)$, but this relationship becomes insignificant if stratified into a benign and malignant group. It may be noticed however that in a malignant group an inverse relationship was present $(\mathrm{R}=-0.32)$ while benign tumors showed positive one $(\mathrm{R}=0.28)$. The PASS index ranged from 1 to 11 (average 3.93, SD 3.55). Obviously, the PASS index was higher in the malignant group (9.25 vs. 2.0).

The number of chymase- and tryptase-positive cells is shown in Table II, and the vessel counts in Table III. No significant differences in these parameters were observed between benign and malignant tumors, neither with the sex of the patient nor laterality (Fig. 1, 2).

Age of the patients was inversely correlated with all mast cells' and vascular counts, with the strongest relationship with intratumoral chymase-positive cells $(\mathrm{R}=-0.39)$. The tumor diameter was positively correlated with all mast cell counts, but only a relation- ship to subcapsular chymase-positive cells was statistically significant $(\mathrm{R}=0.55, \mathrm{p}<0.04)$. For mitotic index, the strongest positive correlate was intratumoral CD105-positive vessel count $(\mathrm{R}=0.35)$, while strongest negative was subcapsular tryptase-positive cells $(\mathrm{R}=-0.32)$. PASS index was inversely correlated with all mast cell counts, with intratumoral tryptase-positive cells being the strongest $(\mathrm{R}=0.45)$. These correlations were even stronger and more significant if only benign category was analyzed, with the exception of the PASS index. Because of the small number of cases, we did not further analyze the correlations in the malignant group.

All the vascular counts were positively correlated with mast cells counts, although the correlation coefficient varied greatly; the highest and most significant were the correlations between subcapsular chymase-positive cells and subcapsular CD31-positive vessels count $(\mathrm{R}=0.61, \mathrm{p}<0.016)$, subcapsular tryptase-positive cells and subcapsular CD31-positive vessels count $(\mathrm{R}=0.53, \mathrm{p}<0.044)$ and subcapsular tryptase-positive cells and intratumoral CD31-positive vessels count $(\mathrm{R}=0.52$, $\mathrm{p}<0.46)$. Again, most of these relationships were retained if only benign tumors were analyzed.

\section{Discussion}

Angiogenesis is a prerequisite for the growth, invasion and metastasis of solid tumors including pheochromocytomas. One of the most potent inducers of new blood vessels formation is hypoxia. There are data pointing to the central role of hypoxia pathway activation in pheochromocytoma tumorigenesis 

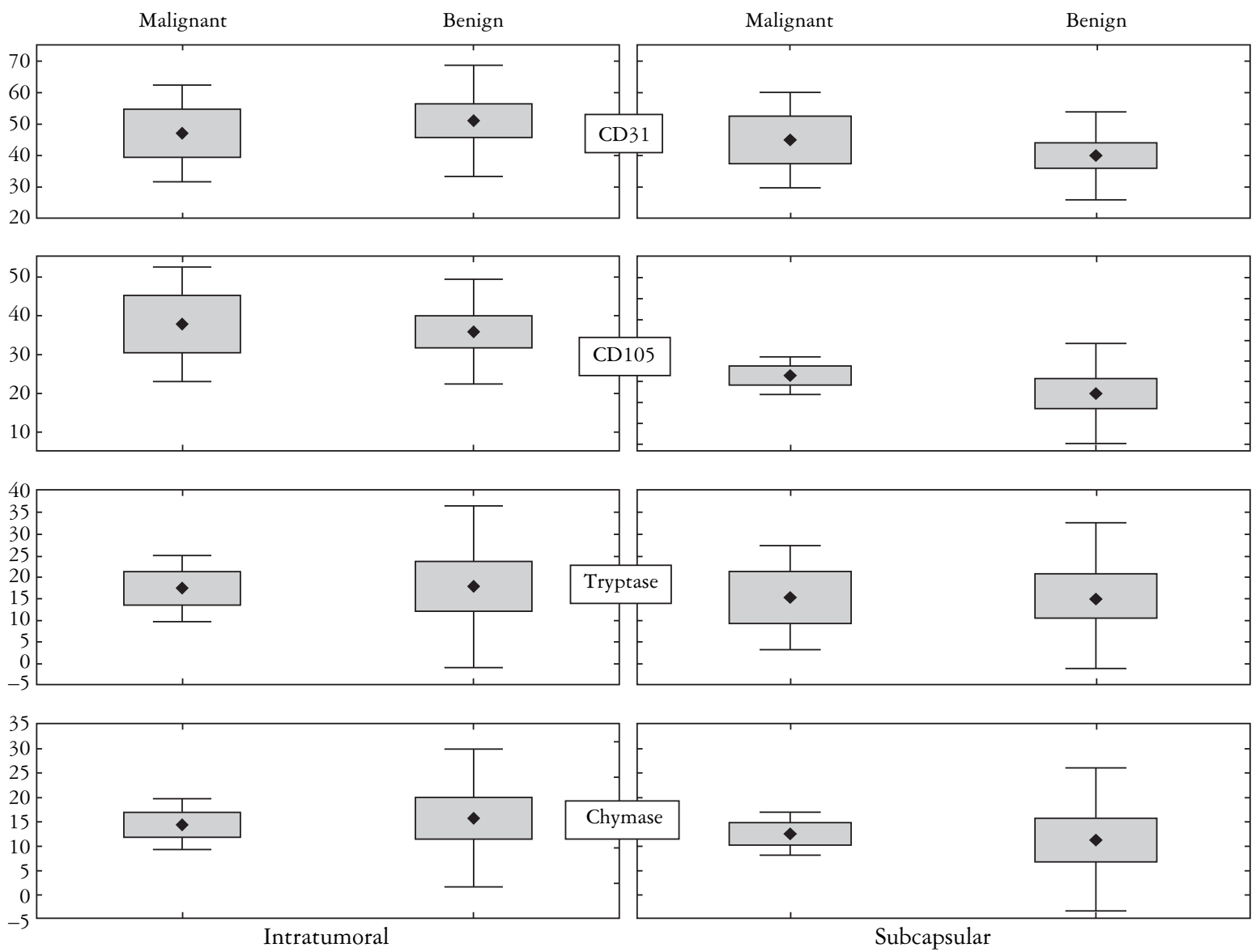

Fig. 1. The values of vascular and mast cells' parameters split between malignant and benign pheochromocytomas. Intratumoral values are shown on the left, subcapsular on the right. The central point is the mean, the box represents standard error and whiskers/asterisk - standard deviation

[10]. Indeed, some von Hippel-Lindau patients develop pheochromocytomas [11]. The expression of markers associated with angiogenesis has been studied in benign and malignant pheochromocytomas and paragangliomas [12]. The expression of vascular endothelial growth factor (VEGF) and hypoxia inducible factor $1 \alpha(\mathrm{HIF}-1 \alpha)$ within tumor cells was demonstrated in experimental models and in human tissue. Increased expression of VEGF and HIF- $1 \alpha$ was noted in malignant pheochromocytomas while benign counterparts showed only a weak expression. Increased expression of VEGF was associated with decreased metastasisfree survival [13-15]. Expression of VEGF cannot be used alone as an indicator of malignancy, though $[10,13]$. Additionally, the genetic status of the patient may influence the VEGF overexpression. Indeed, two different types of pheochromocytoma have been defined by gene expression profiling [10]. Cluster 1 comprises cases associated with hypoxic signature such as succinate dehydrogenase genes (SDHx) and von HippelLindau (VHL) gene-related tumors. Cluster 2 includes tumors with RET proto-oncogene, NF-1 (neurofibromatosis 1 ) and TMEM127 (transmembrane protein
127) genes germline mutations as well as most sporadic tumors [16]. In cluster 1, overexpression of angiopoetin 2, HIF-2 $\alpha$, VEGF in tumor cells and vascular endothelial growth factor receptor- 1 and 2 (VEGFR-1 and VEGFR-2) in endothelium was observed in both malignant and benign pheochromocytomas.

The microvessel density (MVD) has been suggested to be an adverse prognostic indicator for a wide range of tumors such as breast, gastrointestinal, lung, hepatic and urogenital cancers [17]. However, data concerning angiogenesis and prognosis are not fully consistent. There are reports where MVD was not correlated with intratumoral endothelial cell and tumor cell proliferation [18]. In non-small-cell lung carcinoma high MVD is inversely correlated with the risk of distant metastases [19]. In renal cell carcinoma, even an inverse relationship between MVD and patient survival has been observed [20]. That result could depend on intrinsic differences in tumor biology, but could be partly due to the different techniques and antibodies used to quantify tumor blood vessels $[7,21,22]$. The choice of the antibody (e.g. CD34, CD31, von Willebrand factor, or $\mathrm{CD} 105)$ used to detect endothelial cells of the tu- 

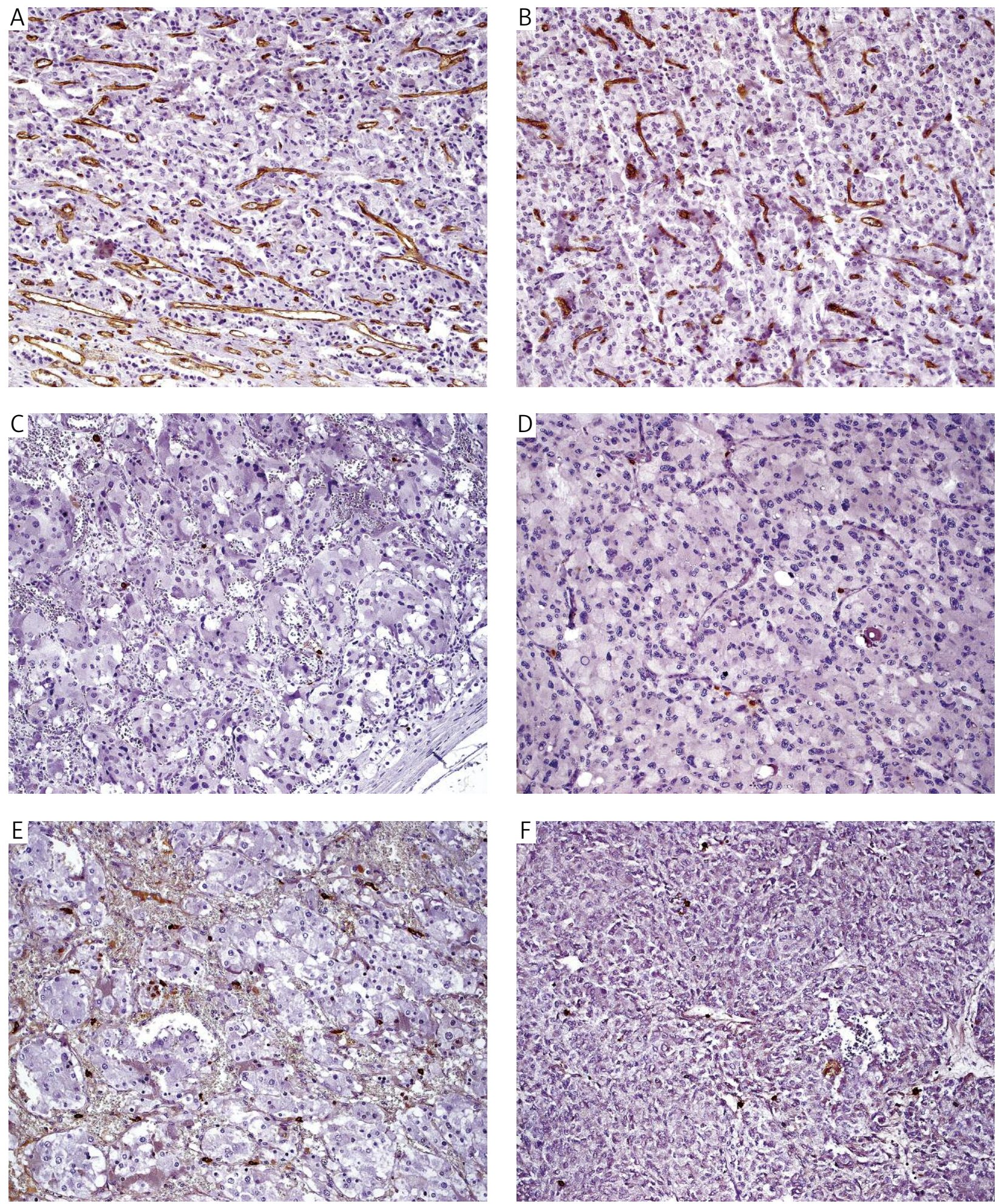

Fig. 2. CD31-positive vessels in benign (A) and malignant (B) pheochromocytoma (top panel), chymase-positive cells in benign (C) and malignant (D) pheochromocytoma (middle panel) and tryptase-positive cells in benign (E) and malignant (F) pheochromocytoma (bottom panel)

mor microvasculature certainly influences the study results, as does the method of measuring vessels density [17]. Selection of a particular area of the tumor for MVD assessment may also play a role. Vascular density is not homogenous throughout the tumor. It has been suggested that the angiogenesis deep inside the tumor is related more to remodeling and migration of endothelial cells while most robust endothelial proliferation occurs at the tumor periphery [23]. In early reports on angiogenesis in pheochromocytomas, the num- 
ber of blood vessels correlated with the invasive behavior [24]. Feng [14], Zielke [15] and Roojens [25] have observed a significantly greater number of blood vessels in metastasizing tumors. However, other authors did not confirm these results $[13,26,27]$.

In the present study, we used anti-CD31 antibody because of its relative specificity for blood vessel endothelia [22]. The other marker studied was endoglin (CD105) that is preferentially expressed in the activated endothelia. Choice of such markers should allow for a better characterization of the angiogenic process $[7$, 281. CD31 and CD105-positive vessels were counted in the inner tumor area and at the tumor periphery. Our study did not reveal any significant difference in MVD between malignant and benign groups regardless of the tumor area. This may be due to the limited number of analyzed cases, especially of the less common malignant ones.

Microvessel density not necessarily correlates with angiogenic dependence of a tumor. It has been recently shown that overall vascular density in prostatic carcinoma is identical to the normal organ; this analysis was based on evaluation of the overall number of tumor vessels, while the previous studies showing increased MVD were done using the standard 'hot spot' method [9]. The method of microvessels' counting may thus introduce a significant bias. The MVD for human lung, mammary, renal cell, colon carcinomas, as well as glioblastomas or pituitary adenomas are lower than those of their normal tissue counterparts; yet the microvessel density influences the survival [6]. Indeed, the relative paucity of the vascular network in tumors may make angiogenesis the limiting factor in tumor growth. What is more, the crude number of vessels not necessarily reflects the blood supply to the tumor. The tumor-related microvessels are often poorly formed, tortuous and the blood flow may be inefficient, slow or even reversed [29-31]. Lately, it has been proposed that all cancers could be characterized as bearing a proliferative or a tissue remodeling phenotype [32]. If such classification holds, it may explain some of the inconsistencies in angiogenesis studies. The density of blood vessels within a tumor might, to some degree, reflect its metabolic demand [17]. The correlation between mitotic activity and CD105 vessel count found in our study may support such hypothesis.

Angiogenesis is an extremely complex process. Many humoral and cellular mechanisms are involved in its initiation and regulation. The microcirculation of tumors can be heterogeneous and consists of purely angiogenic vessels, co-opted vessels (i.e. original vessels of an organ incorporated into the growing tumor) and mosaic vessels. What is more, certain cancers may develop channels to transport plasma and red cells which mimic the function of blood vessels but lack endothelial lining. Those channels may be lined by tumor cells or be composed of looping matrix structures, and form anastomoses with blood vessels. This phenomenon, called vasculogenic mimicry, has been described in a variety of cancers including malignant pheochromocytomas [33]. Therefore, the evaluation of a single parameter of angiogenesis may be biased.

The participation of mast cells (MCs) in various pathologic processes gained some interest in the last years. In particular, MCs are thought to be active stimulators of angiogenesis in cancer. In humans, two populations of MCs can be recognized, depending on the expression of serine proteases stored in their granules. One population is composed of cells containing only tryptase while the second contains both tryptase and chymase. These proteases may exert different biological functions: tryptase stimulates endothelial cells proliferation and degrades connective tissue matrix by activating metalloproteinases and plasminogen activator with subsequent release of matrix bound VEGF and FGF-2. Chymase cleaves pro-metalloproteinase 9 (proMMP-9) into active metalloproteinase 9 (MMP-9, gelatinase $\mathrm{B}$ ), which is involved in angiogenesis and stromal remodeling. Chymase is also responsible for inactivation of tissue inhibitor of MMP. Mast cells contribute to angiogenesis not only via degradation of extracellular matrix. In humans (but not in laboratory animals) chymase generates angiotensin II (AT2) from angiotensin I. This is thought to be a non-standard angiotensin converting mechanism, probably important in pathogenesis of renal and cardiovascular disease [34]. Angiotensin II is also one of the angiogenic factors. Activated MCs secrete a wide variety of proangiogenic factors like VEGFs, angiopoietin, basic fibroblast growth factor (bFGF), transforming growth factor $\beta$ (TGF- $\beta$ ), tumor necrosis factor $\alpha($ TNF- $\alpha)$ and interleukin 8 (IL-8). Other MCs derived mediators with angiogenic properties include histamine and heparin $[6,35,36]$.

An association between MCs and neoangiogenesis has been reported in solid tumors and in hematological malignancies. The correlation between the MCs number and vascular density was observed in breast, gastric, colorectal, endometrial and oral cancers, melanomas and non-small cell lung carcinomas [6]. Tryptase-positive MCs count correlated with MVD in sentinel lymph nodes containing breast cancer micrometastases as well as in early breast cancer [37]. The number of microvessels was shown to be correlated with tryptase-positive MCs and rose with the progression of endometrial carcinoma [38]. The degree of vascularization and both tryptase and chymase-positive MCs increases parallel to the grade of gastric cancers [39]. In another study on gastric carcinoma, the numbers of chymase-positive MCs and MVD was significantly increased in undifferentiated tumors [31]. Similarly in uterine cervix, MVD and density of MCs increases from normal samples through intraepithelial lesions to invasive carcinoma [41]. 
On the other hand, there are studies where no correlation between mast cell density and angiogenesis was observed. Erol et al. have seen no correlation between the mast cell count, microvessels density and grade of endometrial carcinoma [42]. In renal cell carcinoma, mast cell density was not associated with the tumor status such as grade, size, and the number of blood vessels [43]. Renal cell carcinoma may however be a special case, as its most frequent variant, clear cell, is distinctly hypoxia-pathway driven [44].

The extent degree of MCs contribution to angiogenesis may depend on mast cells subtype and location within a tumor. In the central portion of non-small cell lung carcinoma, a significant correlation between chymase-positive MCs and MVD was described, while in the peripheral region the MCs number of both subtypes correlated with MVD. Nevertheless, the highest mast cell count and MVD were observed at the tumor periphery [45, 46].

Most studies suggest that peritumoral mast cells are more abundant than intratumoral ones; also, intratumoral mast cells contain fewer granules. The MCs located in different compartments may have different significance. In prostate cancer, a high intratumoral count was indentified as a good prognostic sign, while patients with a high subcapsular MCs count fare significantly worse than those with a low one [47]. In our previous study, we analyzed mast cells in benign nevi, dysplastic nevi and melanomas and the lowest count of chymasepositive and tryptase-positive cells were observed in the melanoma group both intra- and peritumorally [48].

In the present study, mast cells density correlated with CD31 vessels mainly in the subcapsular region of pheochromocytomas and there were no significant differences between malignant and benign tumors. Additionally, tryptase-positive count was inversely correlated with mitotic activity and PASS index. These results may suggest the contribution of the mast cells to survival of the tumor cells rather than to proliferation and tumor expansion.

Alternatively, it can be assumed that angiogenic switch in pheochromocytomas develops rather in a qualitative than quantitative fashion and expression of growth factors (VEGF, FGF-2 etc.) is a more reliable indicator of angiogenic dependence than MVD and MCs density [13]. VEGF is expressed not only by pheochromocytoma cells but also by mast cells, therefore comparison of mast cells VEGF expression in malignant and benign pheochromocytomas would be rational.

We have also shown an inverse correlation between MCs count and mitotic activity in the inner tumor area and tumor periphery. This, along with a negative correlation of PASS index with intratumoral chymasepositive MCs may support the idea that mast cells may act as an element of immune surveillance [48]. It is postulated that mast cells can play a role in inhibition of tumor growth by a variety of mechanisms: directly, by induction of apoptosis, decreased cell mobility or increased antitumor inflammatory reaction.

\section{Conclusions}

Mast cells may participate in the vessels formation in pheochromocytoma. We have seen no difference in angiogenesis or mast cell count between benign and malignant tumors. Analysis of larger series, especially with more malignant cases, is needed to elucidate this issue.

This work was partly supported by the Ministry of Education, grant no. N402 684340 awarded to Magdalena Biatas.

The authors declare no conflict of interest.

\section{References}

1. Miettinen M. Paragangliomas in modern soft tissue pathology - tumors and non-neoplastic conditions. Cambridge University Press, New York 2010; 755-774.

2. McNicol AM. Update on tumours of adrenal cortex, pheochromocytoma and extra-adrenal paraganglioma. Histopathology 2011; 58: 155-168.

3. DeLellis RA, Lloyd RV, Heitz PU, et al. Tumours of endocrine organs - pathology and genetics, WHO classification of tumours. IARC Press, Lyon 2004; 147-158.

4. Thompson LD. Pheochromocytoma of the Adrenal gland Scaled Score (PASS) to separate benign from malignant neoplasms: a clinicopathologic and immunophenotypic study of 100 cases. Am J Surg Pathol 2002; 26: 551-566.

5. Parenti G, Zampetti B, Rapizzi E, et al. Updated and new perspectives on diagnosis, prognosis and therapy of malignant pheochromocytoma/paraganglioma. J Oncol 2012; 2012: 872713.

6. Ribatti D, Crivellato E. Mast cells, angiogenesis and tumour growth. Biochim Biophys Acta 2012; 1822: 2-8.

7. Sharma S, Sharma MC, Sarkar C. Morphology of angiogenesis in human cancer: a conceptual overview, histoprognostic perspective and significance of neoangiogenesis. Histopathology 2005; 46: 481-489.

8. Vermeulen PB, Gasparini G, Fox SB, et al. Second international consensus on the methodology and criteria of evaluation of angiogenesis quantification in solid human tumors. Eur $\mathrm{J}$ Cancer 2002; 38: 1564-1579.

9. Tretiakova M, Antic T, Binder D, et al. Microvessel density is not increased in prostate cancer: digital imaging of routine sections and tissue microarrays. Hum Pathol 2012; doi: 10.1016/j.humpath.2012.06.009.

10. Span PN, Rao JU, Oude Ophuis SB, et al. Overexpression of the natural antisense hypoxia-inducible factor- 1 alfa transcript is associated with malignant pheochromocytoma/paraganglioma. Endocr Relat Cancer 2011; 18: 323-331.

11. Kurban G, Hudon V, Duplan E, et al. Characterization of a von Hippel-Lindau pathway involved in extracellular matrix remodeling, cell invasion, and angiogenesis. Cancer Res 2006; 66: 1313-1319.

12. Favier J, Gimenez-Roqueplo AP. Pheochromocytomas: the (pseudo)-hypoxia hypothesis. Best Pract Res Clin Endocrinol Metab 2010; 24: 957-968.

13. Salmenkivi K, Heikkilä P, Liu J, et al. VEGF in 105 pheochromocytomas: enhanced expression correlates with malignant outcome. APMIS 2003; 111: 458-464. 
14. Feng F, Zhu Y, Wang X, et al. Predictive factors for malignant pheochromocytoma: analysis of 136 patients. J Urol 2011; 185: 1583-1590.

15. Zielke A, Middeke M, Hoffmann S, et al. VEGF-mediated angiogenesis of human pheochromocytomas is associated to malignancy and inhibited by anti-VEGF antibodies in experimental tumors. Surgery 2002; 132: 1056-1063.

16. Favier J, Igaz P, Burnichon N, et al. Rationale for anti-angiogenic therapy in pheochromocytoma and paraganglioma. Endocr Pathol 2012; 23: 34-42.

17. Hlatky L, Hahnfeldt P, Folkman J. Clinical application of antiangiogenic therapy: microvessel density, what it does and doesn't tell us. J Natl Cancer Inst 2002; 94: 883-893.

18. Vartanian RK, Weidner N. Correlation of intratumoral endothelial cell proliferation with microvessel density (tumor angiogenesis) and tumor cell proliferation in breast carcinoma. Am J Pathol 1994; 144: 1188-1194.

19. Pezzella F, Pastorino U, Tagliabue E, et al. Non-small-cell lung carcinoma tumor growth without morphological evidence of neoangiogenesis. Am J Pathol 1997; 151: 1417-1423.

20. Delahunt B, Bethwaite PB, Thornton A. Prognostic significance of microscopic vascularity for clear cell renal cell carcinoma. $\mathrm{Br}$ J Urol 1997; 80: 401-404.

21. Weidner N, Semple JP, Welch WR, Folkman J. Tumor angiogenesis and metastasis - correlation in invasive breast carcinoma. N Engl J Med 1991; 324: 1-8.

22. Białas M, Okoń K, Czopek J. Assessing microvessel density in gastric carcinoma: a comparison of three markers. Pol J Pathol 2003; 54: 249-252.

23. Giatromanolaki A, Koukourakis MI, Sivridis E, et al. 'Invading edge vs. inner' (edvin) patterns of vascularization: an interplay between angiogenic and vascular survival factors defines the clinical behavior of non-small cell lung cancer. J Pathol 2000; 192: 140-149.

24. Liu Q, Djuricin G, Staren ED, et al. Tumor angiogenesis in pheochromocytomas and paragangliomas. Surgery 1996; 120: 938-943.

25. Rooijens PP, de Krijger RR, Bonjer HJ, et al. The significance of angiogenesis in malignant pheochromocytomas. Endocrine Pathol 2004; 15: 39-46.

26. Fox SB, Leek RD, Weekes MP, et al. Quantitation and prognostic value of breast cancer angiogenesis: comparison of microvessel density, Chalkley count and computer image analysis. J Pathol 1995; 177: 275-283.

27. Ohji H, Sasagawa I, Iciyanagi O, et al. Tumour angiogenesis and $\mathrm{Ki}-67$ expression in pheochromocytoma. BJU Int 2001; 87: 381-385.

28. Kumar P, Wang JM, Bernabeu C. CD 105 and angiogenesis. J Pathol 1996; 178: 363-366.

29. Carmeliet P, Jain RK. Angiogenesis in cancer and other diseases. Nature 2000; 407: 249-257.

30. Fukumura D, Duda DG, Munn LL, Jain RK. Tumor microvasculature and microenvironment: novel insights through intravital imaging in preclinical models. Microcirculation 2010; 17: 206-225.

31. Jain RK. Delivery of molecular medicine to solid tumors: lessons from in vivo imaging of gene expression and function. J Control Release 2001; 74: 7-25.

32. Markert EK, Levine AJ, Vazquez A. Proliferation and tissue remodeling in cancer: the hallmarks revisited. Cell Death Dis 2012; 3: e397.

33. Folberg R, Maniotis AJ. Vasculogenic mimicry. APMIS 2004; 112: $508-525$

34. Hollenberg NK. Implications of species difference for clinical investigation, studies on the renin-angiotensin system. Hypertension 2000; 35: 150-154

35. Maltby S, Khazaie K, McNagny KM. Mast cells in tumor growth: angiogenesis, tissue remodeling and immune-modulation. Biochim Biophys Acta 2009; 1796: 19-26.
36. Crivellato E, Nico B, Ribatti D. Mast cell contribution to tumor angiogenesis: a clinical approach. Eur Cytokine Netw 2009; 20: 197-206.

37. Ranieri G, Ammendola M, Patruno R, et al. Tryptase-positive mast cells correlate with angiogenesis in early breast cancer patients. Int J Oncol 2009; 35: 115-120.

38. Ribatti D, Finato N, Crivellato E, et al. Neovascularization and mast cells with tryptase activity increase simultaneously with pathologic progression in human endometrial cancer. $\mathrm{Am} \mathrm{J} \mathrm{Ob-}$ stet Gynecol 2005; 193: 1961-1965.

39. Ribatti D, Guidolin D, Marzullo A, et al. Mast cells and angiogenesis in gastric carcinoma. Int J Exp Pathol 2010; 91: 350-356.

40. Kondo K, Muramatsu M, Okamoto Y, et al. Expression of chymase-positive cells in gastric cancer and its correlation with the angiogenesis. J Surg Oncol 2006; 93: 36-43.

41. Wilk M, Liszka $E$, Palen $P$, et al. Intensity of angiogenesis and mast cell infiltration in cervical intraepithelial and invasive lesions - are they correlated? Pathol Res Pract 2010; 206: 217-222.

42. Goksu Erol AY, Tokyol C, Ozdemir O, et al. The role of mast cells and angiogenesis in benign and malignant neoplasms of the uterus. Pathol Res Pract 2011; 207: 618-622.

43. Mohseni MG, Mohammadi A, Heshmat AS, et al. The lack of correlation between mast cells and microvessel density with pathologic feature of renal cell carcinoma. Int Urol Nephrol 2010; 42: 109-112.

44. Okoń K. Pathology of renal tumors in adults. Molecular biology, histopathological diagnosis and prognosis. Pol J Pathol 2008; 59: $129-176$

45. Ibaraki T, Muramatsu M, Takai S, et al. The relationship of tryptase- and chymase-positive mast cells to angiogenesis in stage I non-small cell lung cancer. Eur J Cardiothorac Surg 2005; 28: 617-621.

46. Carlini MJ, Dalurzo MC, Lastiri JM, et al. Mast cell phenotypes and microvessels in non-small cell lung cancer and its prognostic significance. Human Pathol 2010; 41: 697-705.

47. Dyduch G, Kaczmarczyk K, Okoń K. Mast cells and cancer: enemies or allies? Pol J Pathol 2012; 1: 1-7.

48. Dyduch G, Okoń K, Pescarini E. Mast cells in melanocytic skin lesions. An immunohistochemical and quantitative study. Pol J Pathol 2011; 3: 139-144.

\section{Address for correspondence}

\section{Magdalena Białas MD}

Department of Pathomorphology

ul. Grzegórzecka 16

31-351 Kraków

tel. +48124211564

e-mail: mbialas7@gmail.com 